\title{
SÍTIOS ARQUEOLÓGICOS DE PEQUENO PORTE DO BAIXO RIO AGUAPEÍ
}

\author{
Diana Mirela da Silva Toso, Neide Barrocá Faccio \\ Universidade Estadual Paulista - UNESP. E-mail: dianamstoso@gmail.com
}

\section{RESUMO}

O presente estudo voltou-se para a análise do contexto de sítios arqueológicos indígenas de pequeno porte, localizados na área do Baixo Rio Aguapeí, margem esquerda, tendo como enfoque para o caso, o Sítio Arqueológico Aldeia I, localizado no município de Junqueirópolis, SP. O estudo foi realizado pelo viés do conceito de paisagem, estimulado pelas contribuições teóricas da Geografia Cultural. O Sítio Arqueológico Aldeia I é constituído por 38 fragmentos de vasilhas cerâmicas, característicos da tradição arqueológica Tupi Guarani, cujas cerâmicas arqueológicas identificadas são fragmentos de vasilhas, com predomínio de tratamento de superfície lisa, espessura média de até $2 \mathrm{~cm}$, e antiplástico mineral com caco moído, constituindo-se como um sítio associado ao Sistema Regional de Ocupação Guarani. O Sítio Arqueológico Aldeia I, quanto à sua implantação e características materiais, apresenta semelhanças em relação aos sítios arqueológicos guarani evidenciados na região.

Palavras-chave: Sítios Arqueológicos de pequeno porte. Sistema Regional de Ocupação Guarani. Planalto Ocidental Paulista.

\section{SMALL ARCHAEOLOGICAL SITES OF THE LOWER AGUAPEÍ RIVER}

\begin{abstract}
The present study focused on the analysis of the context of small archaeological sites, located in the area of the Lower Aguapeí River, left bank, focusing on the case, the Archaeological Site Aldeia I, located in the municipality of Junqueirópolis, SP. The study was carried out by the bias of the landscape concept, stimulated by the theoretical contributions of Cultural Geography. The Archaeological Site Aldeia I consists of 38 fragments of ceramic canisters, characteristic of the archaeological tradition Tupi Guarani, whose archaeological ceramics identified are fragments of canisters, with predominance of smooth surface treatment, average thickness of up to $2 \mathrm{~cm}$, and mineral antiplastic with ground caco, constituting a site associated with the Regional System of Guarani Occupation. The Archaeological Site Aldeia I, as to its implementation and material characteristics, presents similarities in relation to the archaeological sites evidenced in the region.
\end{abstract}

Keywords: Small Archaeological Sites. Regional System of Guarani Occupation. Western Plateau of São Paulo.

\section{INTRODUÇÃO}

Buscando compreender o contexto de sítios arqueológicos de pequeno porte, dedicamo-nos, neste estudo, a analisar e interpretar o Sítio Arqueológico Aldeia I, e apresentar os sítios identificados no Baixo Rio Aguapeí - margem esquerda -, caracterizando sua área de implantação no compartimento topográfico, na proximidade de cursos d'água, na variabilidade de peças arqueológicas e, também, na extensão do sítio arqueológico.

Os sítios analisados foram encontrados por meio da prática da arqueologia preventiva, que avalia o impacto ao patrimônio arqueológico, causado por obras e práticas humanas, dentre elas a da agroindústria - principalmente aquelas 
produtoras de açúcar e álcool, por meio do cultivo de cana-de-açúcar.

Para compreender o contexto

arqueológico no Baixo Rio Aguapeí, apresentamos sítios de pequeno porte encontrados no Vale do Paranapanema e estudados por Faccio (1998) e Pereira (2011), consolidando bases para análise e interpretação dos sítios arqueológicos aqui apresentados.

A terminologia Sítios de pequeno porte foi utilizada na obra de Faccio (1998) para diferenciar sítios no vale do Rio Paranapanema, a partir de sua distância em relação aos cursos d'água nas proximidades, ao tipo de curso d'água próximo, à extensão do sítio arqueológico e à quantidade de peças arqueológicas.

É de salutar importância ressaltarmos que junto a análise das peças cerâmicas a quantidade de peças deve ser analisada pensando que a quantidade em grupos Guarani relaciona-se com o tamanho da implantação. Além disso, leva-se em consideração a variabilidade de vasilhas a partir das características analisadas em cada peça cerâmica.

Essa classificação - sítio de pequeno porte - caracteriza sítios associados à Tradição Tupiguarani ${ }^{1}$, que apresentam no território Paulista grandes aldeias nas proximidades dos Rios Paraná e Paranapanema, mas que, no interior, seguindo afluentes que compõem a bacia hidrográfica desses rios, mudam de dimensão e apresentam menor quantidade e menor variabilidade de peças arqueológicas.

Faccio (1998) estudou oito sítios que apresentam tais características e foram caracterizados como de pequeno porte: Sítio Neves e Sítio Lima, no Município lepê, SP; Sítio Silva, no Município de Taciba, SP; Sítio Marambaia, Sítio Figueiredo no Município de Rancharia, SP; Sítio Campinho, no Município de Florínia, SP; Sítio Graças no Distrito de Gardênia; Sítio Porto Quebra-canoa, no Município de Florínia.

Estes oito sítios caracterizados como de pequeno porte constituem-se como parte de um total de 17 sítios estudados por Faccio (1998), sítio esses de pequeno e grande porte. Entre os oito sítios, sete apresentaram fragmentos cerâmicos (Sítio Neves, Lima, Silva, Marambaia, Campinho, Graças e Porto Quebra Canoa), um apresentou artefato lítico lascado e polido junto aos fragmentos cerâmicos (Sítio Neves), sendo que o lítico polido também foi encontrado em mais três dos sítios citados (Lima, Figueiredo e Campinho) (Tabela 1).

\footnotetext{
${ }^{1}$ A denominação Tradição Tupiguarani, foi dada aos fragmentos cerâmicos que apresentaram em geral pintura policrômica e decoração plástica (escovada, corrugada). As áreas de ocorrência dessas cerâmicas estão associadas aos locais onde estavam assentados grupos indígenas da família Tupi-Guarani, pertencente ao tronco linguístico Tupi.
} 
Tabela 1. Tipos de registros Arqueológicos e quantidade de peças evidenciadas nos sítios da mesoregião da Capivara, Baixo Paranapanema, SP

\begin{tabular}{lllllll}
\hline Sítio Arqueológico & Município & Cerâmica & Polido & Lítico & $\begin{array}{l}\text { Mancha } \\
\text { Preta }\end{array}$ & Peças \\
\hline Marambaia & Rancharia-SP & $\mathrm{x}$ & & & & 11 \\
\hline Neves & Rancharia-SP & $\mathrm{x}$ & $\mathrm{x}$ & $\mathrm{x}$ & $\mathrm{x}$ & 32 \\
\hline Graças & Rancharia-SP & $\mathrm{x}$ & & & & 71 \\
\hline Lima & Rancharia-SP & $\mathrm{x}$ & $\mathrm{x}$ & & & 56 \\
\hline Silva & Taciba-SP & $\mathrm{x}$ & & & & 5 \\
\hline Campinho & Florínia-SP & $\mathrm{x}$ & $\mathrm{x}$ & & & - \\
\hline Figueiredo & Rancharia-SP & & $\mathrm{x}$ & & & - \\
\hline Porto Quebra-Canoa & Cândido Mota-SP & $\mathrm{x}$ & $\mathrm{x}$ & & & \\
\hline
\end{tabular}

Fonte: Faccio (1998). Elaborado pela autora.

Os sítios analisados apresentaram variação de peças cerâmicas, sendo, predominante, fragmentos de parede, seguidos por borda e base. Destaca-se o predomínio dos fragmentos de parede, seguidos por borda, base, ombro, suporte de panela e borda com parede e base (FACCIO, 1998).
O estudo de Faccio (1998) permitiu enquadrar os sítios de grande e de pequeno porte da Mesoregião da Capivara, na Tradição Tupiguarani. Quanto à implantação desses sítios arqueológicos, sintetizamos a caracterização apresentada por Faccio (1998), no Tabela 2.

Tabela 2. Sítios Arqueológicos de pequeno porte evidenciadas na mesoregião da Capivara, Baixo Paranapanema, SP e tipo de implantação

\begin{tabular}{|c|c|c|c|c|}
\hline Sítio Arqueológico & $\begin{array}{l}\text { Compartimento } \\
\text { topográfico }\end{array}$ & $\begin{array}{l}\text { Curso d'água mais } \\
\text { próximo }\end{array}$ & $\begin{array}{l}\text { Fonte de matéria- } \\
\text { prima }\end{array}$ & Peças \\
\hline Marambaia & Encosta & $\begin{array}{lll}\text { Ribeirão Água da } \\
\text { Floresta }\end{array}$ & & $\begin{array}{l}50 \times 80 \mathrm{~m} \\
\left(4000 \mathrm{~m}^{2}\right)\end{array}$ \\
\hline Neves & Meia-encosta & Ribeirão Capivari & $\begin{array}{lr}\text { Cascalheira } & \text { e } \\
\text { nascente de um } \\
\text { Ribeirão } \\
\text { potencial (área } \\
\text { aquisição de argila) }\end{array}$ & 143 \\
\hline Graças & Meia-encosta & $\begin{array}{lll}\text { Ribeirão } & \text { Água da } \\
\text { Fábula } & \text { e uma } \\
\text { nascente } & & \\
\end{array}$ & $\begin{array}{l}\text { Fonte de argila e } \\
\text { cascalheiras }\end{array}$ & $\begin{array}{l}60 \times 100 \mathrm{~m} \\
6000 \mathrm{~m}^{2}\end{array}$ \\
\hline Lima & Meia-encosta & $\begin{array}{l}\text { Ribeirão Água da } \\
\text { Fábula }\end{array}$ & $\begin{array}{l}\text { Fonte de argila e } \\
\text { cascalheiras }\end{array}$ & $2400 \mathrm{~m}^{2}$ \\
\hline Silva & Meia-encosta & $\begin{array}{l}\text { Água da Formiga e } \\
\text { Água do Amargoso }\end{array}$ & $\begin{array}{lr}\text { Afloramento de } \\
\text { basalto e plaquetas } \\
\text { de } \quad \text { arenito } \\
\text { silicificado }\end{array}$ & $9500 \mathrm{~m}^{2}$ \\
\hline Campinho & Meia-encosta & $\begin{array}{l}\text { Represa de Capivara } \\
\text { no } \\
\text { Paranapanema } \\
\end{array}$ & - & - \\
\hline Figueiredo & Meia-encosta & $\begin{array}{l}\text { Nascentes que } \\
\text { formam o Ribeirão } \\
\text { Água da Floresta }\end{array}$ & & - \\
\hline Porto Quebra-Canoa & - & - & - & - \\
\hline
\end{tabular}

Fonte: Faccio (1998). Elaborado pela autora 
Podemos observar o predomínio da ocorrência dos sítios arqueológicos em meia encosta, próximo a fontes de matéria prima e a cursos d'água. Essa preferência dos grupos ceramistas foi identificada por Faccio (1998), tanto nos grandes quanto nos pequenos sítios. Por assentar-se em terraços ou meia encostas próximas a cascalheiras e/ou nascentes de água, esses grupos selecionaram naquele espaço, unidades geográficas de acordo com suas necessidades e com as atividades que pretendiam desenvolver (FACCIO, 1998).

Porém, há uma notável diferença em relação à distância desses sítios de pequeno porte em relação aos maiores cursos d'água, se comparados com os de maior porte, como Faccio (1998) observa:

\begin{abstract}
os sítios de menor porte trabalhados até 0 momento na Mesoregião da Capivara distam do córrego ou riberão entre 100 metros (Sítio Neves) e 180 metros (Sítio Silva) e, do Rio Paranapanema, entre 21 quilômetros (Sítio Graças) e 58 quilômetros (Sítio Marambaia). Os sítios de maior porte como Ragil e Ragil II contam com córrego ou ribeirão na área do sítio e distavam do Rio Paranapanema, antes da formação do lago da UHE da Capivara, em 2,5 e 1,25 quilômetros, respectivamente ( $\mathrm{FACClO}$, 1998, p. 266).
\end{abstract}

Nesse sentido, observamos que os sítios de pequeno porte estudados por Faccio (1998) estão próximos a pequenos cursos d'água (Córregos e Ribeirões), distantes dos grandes rios, se comparados aos de maior porte, localizados próximos à margem do Rio Paranapanema e como em outros casos nas margens do Rio Paraná.

Outra obra voltada à análise e interpretação de sítios de pequeno porte é a de Pereira (2011) que dedicou à análise e interpretação dos registros arqueológicos do Sítio Célia Maria, localizado às margens do córrego Itapiranga, situado na Bacia do Rio Santo Anastácio. Esse sítio arqueológico está em área de interflúvios que separam as Bacias do Paraná e
Paranapanema. Foram estudados 4.715 fragmentos cerâmicos. $O$ sítio também apresenta características de pequeno porte.

Observando as diferenças ocorridas entre sítios que apresentaram características de grande porte com os de pequeno porte, Pereira (2011) explica que a existência desses sítios mais afastados dos grandes rios, com baixa densidade de artefatos, pode representar que "o sistema sócio/cultural guarani definiria hierarquias de ocupação das áreas, partindo das zonas ecológicas mais favoráveis para as menos favoráveis" (PEREIRA, 2011, p. 143). Assim, os sítios de pequeno porte complementariam um sistema sociocultural e representam uma organização de assentamentos com base em características ambientais, juntamente com os sítios de grande e médio porte.

Referindo-se aos sítios de pequeno porte, Pereira (2011) explica,

[...] podem estar
associados a áreas
de acampamento
sazonal r de
atividades de roça.
Essas duas áreas
junto à aldeia
faziam parte de um
sistemarara de
exploração
ecológica,
tipicamente
guarani,
assegurando em
seu território
(tekoá) seu domínio
de influência
político-espacial e
melhor
aproveitamento dos
recursos naturais
(PEREIRA, 2011, p.
135).

Pode ser observado que os sítios de pequeno porte, analisados por Faccio (1998), e o Sítio Célia Maria, analisado por Pereira (2011), apresentam semelhanças no que se refere às características ambientais (Toso, 2018). Indicam ocupações com população pequena e com capacidade para ali permanecerem por curto período, ou seja, indicam ocupações sazonais, mas que podem estar associadas a um sistema de exploração ecológica tipicamente Guarani, como exposto por Pereira (2011). 


\section{DELINEAMENTO METODOLÓGICO}

Para as análises dos materiais arqueológicos cerâmicos do Sítio Arqueológico Aldeia I, foram utilizados 38 fragmentos.

Analisamos os vestígios arqueológicos, a fim de conhecer a cerâmica nos seus aspectos tecnotipológicos e, assim, poder associá-la às Cerâmicas Guarani ou diferenciá-la daquelas encontradas em outros sítios arqueológicos Guarani do Oeste Paulista.

Buscamos, em nossas análises, compreender a funcionalidade do artefato que nos revela a intenção do (a) artesão (ã) na produção daquela peça, considerando os elementos: antiplástico, pasta, classe do fragmento, espessura, queima, tratamento de superfície e decoração. Trata-se de uma análise estrutural, como proposto por La Salvia e Brochado (1989), "onde as partes dos componentes do todo são estudadas e integradas de forma tal que um conjunto maior se apresente e que o universo da cultura surja de forma mais consistente".

Revela-se como uma análise de observação e forma de desenvolvimento analítico por meio de uma visão morfológica, que descreve o que se vê, mas que busca a razão do por que se faz (LA SALVIA; BROCHADO, 1989), ou seja, buscamos compreender, por meio dos elementos analisados em cada vestígio, a funcionalidade, visto que os vestígios analisados são o fim de um comportamento cultural; afinal, representam a existência de uma população indígena, que produzia cerâmica para suprir as necessidades de sua população.

Nesse sentido, constata-se que o registro arqueológico apresenta em si um processo produtivo, baseado em uma necessidade. Como afirmam La Salvia e Brochado (1989),

[...] o princípio de
nosso trabalho é o
fim de um
comportamento
cultural. O registro
arqueológico é a
constatação da
existência de um
remanescente
cultural
representado por
fragmentos
abandonados ou
vasilhas inteiras
intencionalmente
dispostas dentro de

um cerimonial. (LA

SALVIA;

BROCHADO, $1989 \mathrm{p}$.

10).

O processo produtivo varia de acordo com a intenção de cada artesão. Como afirmam Brochado e La Salvia (1989), "o processo é um complexo de ações que seguem um conjunto desde a base até a borda, onde não só a construção, mas os tipos de acabamentos são e serão desenvolvidos".

Ainda de acordo com La Salvia e Brochado (1989), o processo produtivo conta com seis principais ações: preparação da pasta, preparação do artefato, técnica de elaboração, aplicação do acabamento decorativo, queima e, por fim, utilização. Essas seis principais ações possuem em si particularidades que serão escolhidas pelo artesão, de acordo com seu objetivo de produção.

O modo de produção, também chamado como técnica de elaboração, praticado pelos indígenas Guarani é o acordelado, ação de fabricação de vasilhas a partir da sobreposição de roletes de argila. Essa argila é escolhida pelo artesão, de acordo com a sua intenção. Podemos identificar nela o que chamamos de antiplástico, elemento que pode ser adicionado ou preexistir, dentro da argila, e que diminui a sua plasticidade (LA SALVIA; BROCHADO, 1989).

A associação entre argila e antiplástico é o que definimos como pasta. Como La Salvia e Brochado (1989) esclarecem, a pasta é um elemento importante na definição do modo de produção, utilização e acabamento de cada peça. Essa pasta pode ser preparada pelo artesão (ã) com intencionalidade diferente para os roletes destinados à fabricação do artefato ou para aplicação na face externa da peça (barbotina).

\section{RESULTADOS E DISCUSSÃO}

O Sítio Aldeia I está localizado na subbacia do Baixo Aguapeí, na qual foram identificados outros sítios cerâmicos. Esses sítios arqueológicos foram encontrados em 2013, junto ao Sítio Aldeia I, pela equipe de Faccio (2013), que realizou diagnóstico prospectivo na região. Esses sítios têm sido estudados por pesquisadores do Laboratório de Arqueologia Guarani e Estudos da Paisagem da Faculdade de Ciências e Tecnologia, da Universidade Estadual Paulista (UNESP), campus de Presidente Prudente. 
Os sítios arqueológicos cerâmicos identificados nessa região estão distribuídos em quatro municípios, sendo o Sítio Aldeia I, Aldeia II, Nova Palmeira e Areia Branca em Junqueirópolis, SP, Jaobi e Corredeira em Tupi
Paulista, Córrego da Paz e Kandiri em Pacaembu e Sítio Dracena no Município de Dracena. Ainda, foram encontradas três áreas de ocorrência com materiais cerâmicos na mesma região: Ariranha, Sertãozinho e Paturizinho (Figura 1).

Figura 1. Sítios Arqueológicos com materiais cerâmicos do Baixo Rio Aguapeí em relação aos munícipios e hidrografia.

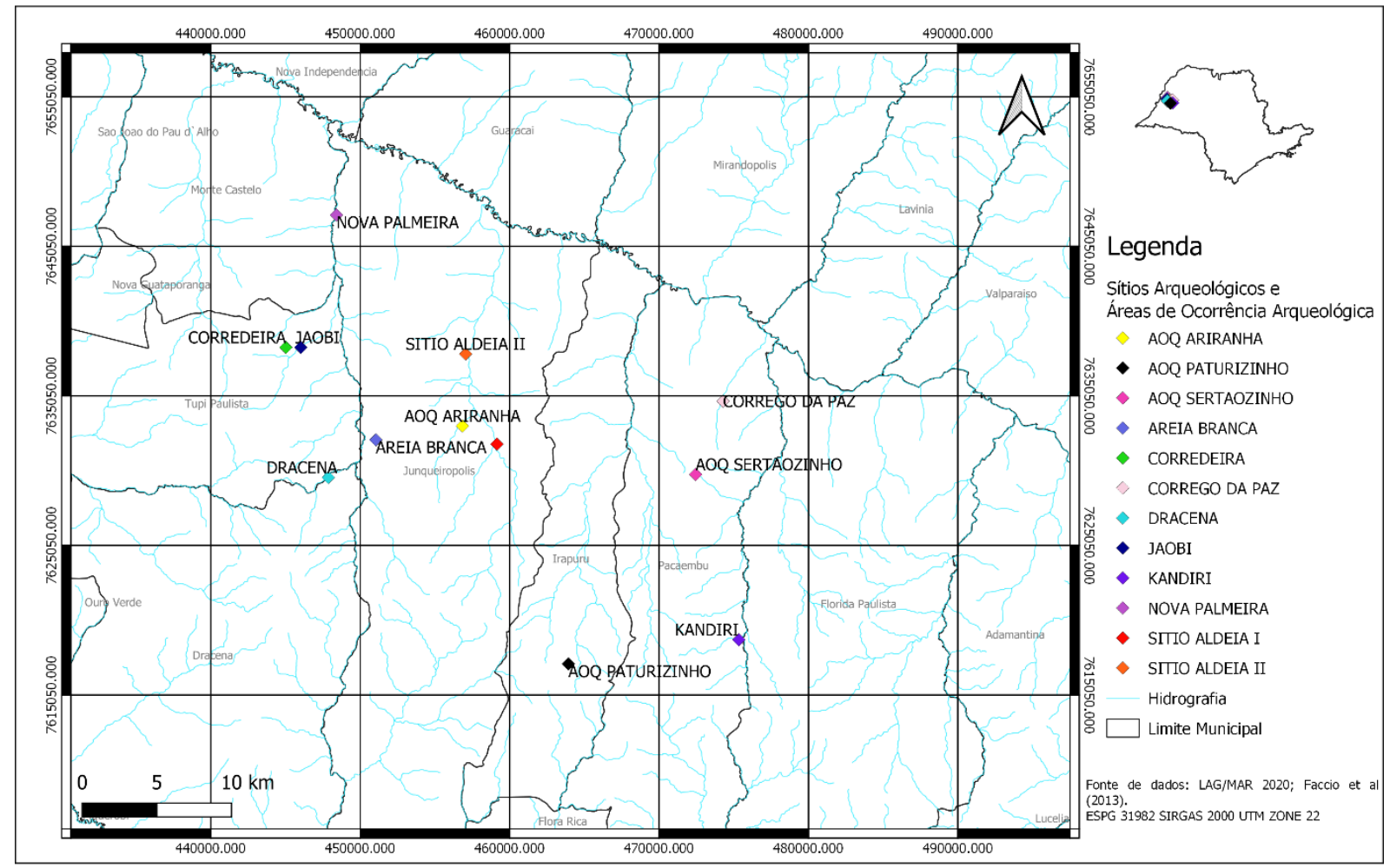

Fonte: Faccio et al 2013. Elaboração: a autora

No município de Junqueirópolis, SP, localizam-se o Sítio Aldeia I, o Sítio Aldeia II, o Sítio Nova Palmeira e o Sítio Areia Branca.

O Sítio Arqueológico Aldeia I, localizado em baixa vertente, próximo ao Ribeirão Taquaruçu, apresentou 38 fragmentos cerâmicos e um lítico polido.

O Sítio Arqueológico Aldeia II está implantado na baixa vertente de colina ampla e com declive suave, próximo ao Ribeirão Taquaruçu. A cerâmica do Sítio Aldeia II apresentou o antiplástico mineral associado ao caco moído e o antiplástico mineral. Foi identificado um aplique antropomórfico, um aplique mamilar, 19 bases, uma base/calibrador, 34 bordas, 145 paredes, oito paredes angulares e um fragmento de parede/calibrador, totalizando 210 peças. A decoração predominante foi o tipo liso na face interna e externa (183 peças), seguida por face interna não identificada e liso na face externa (oito peças), engobo na face interna e liso na externa (seis peças), liso na interna e pintado na externa (cinco peças), pintado na face interna e liso na externa (quatro peças) e, por fim, uma peça com tipo de decoração liso na face interna e pseudoungulado na face externa, uma peça com tipo liso na interna e apêndice na externa, uma peça com tipo liso na interna e corrugado na externa e uma peça com tipo liso na interna e não identificado na externa.

\section{O Sítio Arqueológico Nova Palmeira} configura-se como um sítio a céu aberto, localizado na propriedade rural denominada Fazenda Nossa Senhora Aparecida (G 53), no Município de Junqueirópolis, SP. O sítio foi evidenciado em uma planície, nas proximidades do Ribeirão Nova Palmeira, região da Bacia Hidrográfica do Rio Aguapeí. Foi encontrada uma jazida de argila a 90 metros de distância da maior concentração de fragmentos do Sítio Nova Palmeira.

Entre as categorias de fragmentos cerâmicos do Sítio Nova Palmeira foram encontrados dez fragmentos de parede angular, 
Tabela 3. Distribuição por classe dos fragmentos cerâmicos do Sítio Arqueológico Nova Palmeira, Junqueirópolis, SP.

\begin{tabular}{lll}
\hline Categoria & Quantidade de peças & $\%$ \\
\hline Base & 35 & 2,9 \\
\hline Bolota de argila queimada & 1 & 0,1 \\
\hline Borda & 220 & 18,1 \\
\hline Borda com suporte para tampa & 1 & 0,1 \\
\hline Calibrador & 28 & 2,3 \\
\hline Fragmento de colher & 1 & 0,1 \\
\hline Fragmento de vaso conjugado & 1 & 0,1 \\
\hline Parede & 919 & 75,6 \\
\hline Parede angular & 10 & 0,8 \\
\hline Total & 1216 & 100 \\
\hline
\end{tabular}

Fonte: Faccio et al. (2013). Elaboração: a autora

A decoração dos fragmentos do sítio Nova Palmeira apresentou-se diversificada (18 variações), predominando o tipo liso na face interna e externa, seguido pelo tipo liso na face interna e pintado na face externa. (Tabela 4)

O Sítio Arqueológico Areia Branca está localizado próximo a uma nascente na planície alagadiça do Ribeirão Nova Palmeira. É um sítio com pequena densidade de material arqueológico. Foram encontrados ali cinco líticos lascados no resgate e apenas dois fragmentos cerâmicos.

O Sítio Aldeia I ocupa a baixa vertente, próximo ao Ribeirão Taquaruçu, pertencente à Bacia Hidrográfica do Rio Aguapeí. O solo na área é caracterizado pela qualidade homogênea, de tipo arenoso a areno-argiloso, bruno a bruno avermelhado, médio.

No Município de Tupi Paulista, SP, foram encontrados dois sítios arqueológicos, o Sítio Jaobi e o Sítio Corredeira. O Sítio Arqueológico Jaobi, está em uma planície, nas proximidades do Ribeirão Nova Palmeira. Desse sítio, foram estudados 42 fragmentos de cerâmica. Apresentou, em todos os casos, antiplástico mineral associado ao caco moído. O tipo de decoração predominante foi o liso na face interna e externa. O Sítio Arqueológico Corredeira apresentou apenas um fragmento de borda, com decoração tipo liso tanto na face interna quanto na externa.

Tabela 4. Distribuição dos tipos de decoração dos fragmentos cerâmicos do Sítio Arqueológico Nova Palmeira, Junqueirópolis, SP.

\begin{tabular}{lll|lll}
\hline Tipo interno/ externo & Qtd. de & \% & Tipo interno/ externo & Qtd. de & peças \\
& peças & & & & \\
\hline Engobo branco/Pintado & 1 & 0,1 & Liso/ Pseudoungulado & 1 & 0,1 \\
\hline Engobo branco/ Liso & 1 & 0,1 & Liso/ Ponteado & 2 & 0,2 \\
\hline Engobo vermelho/ Liso & 1 & 0,1 & Liso/ Serrungulado & 6 & 0,5 \\
\hline Engobo vermelho/ E. vermelho & 1 & 0,1 & Liso/ Corrugado & 24 & 2,0 \\
\hline Liso/ Engobo branco & 3 & 0,2 & Não identificado/ Liso & 2 & 0,2 \\
\hline Liso/ Entalhado & 1 & 0,1 & Pintado/ Liso & 105 & 9 \\
\hline Liso/ Inciso & 4 & 0,3 & Pintado/ Pintado & 9 & 0,7 \\
\hline Liso/ Não Identificado & 10 & 0,8 & Liso/ Pintado & 106 & 9 \\
\hline Liso/ Não Identificado & 11 & 0,9 & Liso/ Liso & 928 & 76 \\
\hline \multicolumn{7}{c}{ Total de peças: 1216} & & \\
\hline
\end{tabular}

Fonte: Faccio et al (2013). Elaboração: a autora 
Em Pacaembu, SP, foi evidenciado o Sítio Arqueológico Córrego da Paz, que está localizado em uma planície nas proximidades do Córrego da Paz. Esse sítio apresentou 38 fragmentos, dos quais 33 são paredes, quatro são base e um é borda. A decoração predominante nos fragmentos desse sítio foi o tipo liso tanto na face externa quanto na face interna (31 peças), seguida por engobo branco na face interna e liso na externa (quatro peças), liso na interna com face externa não identificada (duas peças) e, por fim, liso na interna com engobo branco na externa (uma peça). Houve o predomínio do uso do antiplástico mineral associado ao caco moído (90\%). Porém, em alguns casos, utilizou-se somente o antiplástico mineral (10\%). Na área do Sítio Arqueológico Córrego da Paz, foram evidenciados dois líticos lascados na forma de núcleo, que possuem como suporte o seixo e as matérias primas são o silexito e quartzito.

O Sítio Arqueológico Kandiri fica em uma planície situada a menos de 100 metros do Ribeirão Iracema, pertencente à Bacia Hidrográfica do Rio Aguapeí. As cerâmicas encontradas são, em sua maior parte, parede (57 peças), seguidas por base (12 peças) e borda (sete peças). Foi identificado um fragmento de lâmina de machado semilunar, característica de índios do Grupo Jê, da etnia Kaingang ou Kraô. As peças encontradas apresentaram dois tipos de decoração, o tipo liso e o tipo pintado, sendo 69 peças liso interno e externo, cinco liso na face interna e pintado na face externa. Diante das características apresentadas pelo material lítico polido e pela cerâmica, é possível que o Sítio Kandiri possa estar associado à Tradição Itararé, ou seja, ao Sistema Regional de Ocupação Kaingang, proposto por Morais (FACCIO et al., 2013, p. 310).

No Município de Dracena, está localizado - Sítio Arqueológico Dracena com baixa densidade artefatual, apresentando 16 fragmentos de cerâmica lisa, com antiplástico mineral associado ao caco moído e espessura de parede, que variou de 1,2 a 1,6 centímetros (FACCIO et al., 2013, p. 321). O sítio está implantado na média-baixa vertente de uma colina.

No Município de Flórida Paulista, SP, encontra-se o Sítio Arqueológico Alvorada V, na em área de plantio de cana-de-açúcar, em uma planície nas proximidades do Rio Aguapeí. Foram encontrados materiais líticos lascados. Todos os materiais tiveram como suporte o seixo e suas matérias primas foram identificadas como silexito, quartzito e quartzo leitoso.

As áreas dos sítios arqueológicos apresentaram impactos causados pelo uso de maquinários agrícolas pesados, utilizados para o preparo do solo para o cultivo e transporte da cana-de-açúcar (FACCIO et al. , 2013).

Os sítios foram caracterizados como Tradição Tupiguarani, exceto o Sítio Kandiri que apresentou características semelhanças à Tradição Itararé no material lítico polido e na cerâmica.

O Sítio Nova Palmeira apresenta a maior quantidade de fragmentos cerâmicos com 1.216 peças, seguido por Aldeia II (210 peças), Kandiri (76 peças), Jaobi (42 fragmentos), Aldeia I e Córrego da Paz com 38 peças, Dracena com 16, Areia Branca com duas peças e Corredeira com apenas uma (Tabela 5).

Os sítios localizam-se em áreas de encosta e meia encosta, apresentando em suas proximidades pequenos cursos d'água, nascentes e cascalheiras.

Constata-se que os tipos cerâmicos, encontrados na área do Sítio Aldeia I e nos demais sítios, assim como nos sítios estudados por Faccio (1998) e Pereira (2011), são característicos da tradição arqueológica Tupiguarani. 
Tabela 5. Quantidade de fragmentos por Sítio Arqueológico da bacia do Rio Aguapeí, resgatados em 2013.

\begin{tabular}{l|l}
\hline Sítios Arqueológicos & \multicolumn{1}{c}{ Quantidade de peças } \\
\hline Sítio Arqueológico Nova Palmeira & 1216 \\
\hline Sítio Arqueológico Aldeia II & 210 \\
\hline Sítio Arqueológico Kandiri & 76 \\
\hline Sítio Arqueológico Jaobi & 42 \\
\hline Sítio Arqueológico Aldeia & 38 \\
\hline Sítio Arqueológico Córrego da Paz & 38 \\
\hline Sítio Arqueológico Dracena & 16 \\
\hline Sítio Arqueológico Areia Branca & 2 \\
\hline Sítio Arqueológico Corredeira & 1 \\
\hline
\end{tabular}

Fonte: Faccio et al (2013).

Observa-se que o Sítio Aldeia I, assim como os sítios resgatados em sua proximidade na Bacia do Rio Aguapeí e do Peixe, compartilham semelhanças com características identificadas nos sítios de pequeno porte na área do Rio Paranapanema. Os sítios identificados no resgate estão localizados em áreas de encosta e meia encosta, próximos de pequenos cursos d'água e com fonte de matéria prima em suas proximidades, porém as condições sugerem tratar-se de áreas usadas temporariamente, tendo em vista que as condições oferecidas nas proximidades dos maiores rios como o Paraná e o Paranapanema sugerem assentamentos maiores, com capacidade de abrigar uma grande população indígena.

Pereira (2011), com base nos estudos de Pallestrini (1968-69), Morais (1979;1986), Pallestrini e Morais (1984, 1988) e Faccio (1998; 2011), analisa as diferenciações geográficas relacionadas à implantação dos assentamentos no espaço, destacando que os sítios do Alto-Médio Paranapanema localizaram-se em relevos colinares, no topo ou na meia encosta, com cursos d'água na base ou em suas proximidades. Já os sítios do Baixo Paranapanema apresentaram-se, em sua maior parte, nas margens do Rio Paranapanema, em terraços fluviais, com solo de alta fertilidade, devido à decomposição do basalto, oriundo da formação geológica Serra Geral, em média-baixa vertente, próximos a lagos e nascentes com presença de depósitos de argila.

Como explicado, os sítios de pequeno porte distam dos rios navegáveis em maior distância que os identificados com maior densidade de artefatos. O Sítio Aldeia I caracteriza-se como de pequeno porte por essas características, assim como os sítios de seu entorno.
Esses elementos sugerem que se trata de sítios com ocupação sazonal e, como explicado por Pereira (2011), embasado nas interpretações de Brochado (1989), Lathrap (1975), Noelli (1993, 1999-2000) e Soares (1997), a localização desses sítios sugere que tais grupos foram impulsionados a procurar novas terras aptas ao sistema de reprodução cultural a que pertenciam, devido aos seguintes fatores: alta produtividade agrícola que possibilitou o aumento demográfico, privilégios de lideranças de famílias extensas por um líder e acirramento entre lideranças que ocasionavam desmembramentos.

Nesse sentido, os sítios localizados nessas áreas com características ecológicas pertinentes a acampamentos menores e com ocupação por curto período de tempo é resultante de uma organização sociocultural desses indígenas, os quais distam dos grandes assentamentos, mas carregam um sistema cultural, reproduzindo-o em novas áreas, que são escolhidas, também, com base nesse sistema, ou seja, mesmo com características ecológicas diferentes, procuravam uma área que apresentasse, ao menos, a garantia de reprodução de alguns de seus conhecimentos, como terra fértil para plantio, fonte de matéria prima, córrego ou ribeirão para acesso à água e prática da pesca, por exemplo.

Em suma, analisando a localização dos sítios arqueológicos resgatados junto ao Sítio Aldeia I e os sítios estudados pelos autores citados, reforçam a preferência dos grupos indígenas que ocuparam essas diferentes áreas para terraços ou meias encostas próximas a fontes de matéria-prima (rochas, argila, cascalheiras) e/ou nascentes de água.

O Sítio Arqueológico Aldeia I está localizado na Bacia Hidrográfica do Rio Aguapeí, precisamente na sub-bacia Baixo Aguapeí, sendo a primeira limitada ao norte pelo Baixo Tietê e Tietê 
da Batalha, ao sul pela Bacia do Rio do Peixe e Médio Paranapanema.

A Bacia Hidrográfica do Rio Aguapeí está localizada na Bacia Sedimentar do Paraná. Quanto ao seu substrato, é constituído por rochas cretáceas (Formação Santo Anastácio, Adamantina, Marília e basaltos da Formação
Serra Geral), recobertos em áreas de deposição por sedimentos quarternários, sob a forma de depósitos aluviais (planícies atuais e terraços), mantos coluviais e regolitos espessos em pedimentos mais bem preservados (PORTO et al., 2013) (Figura 6).

Figura 6. Unidades litoestratigráficas da Bacia Hidrográfica do Rio Aguapeí

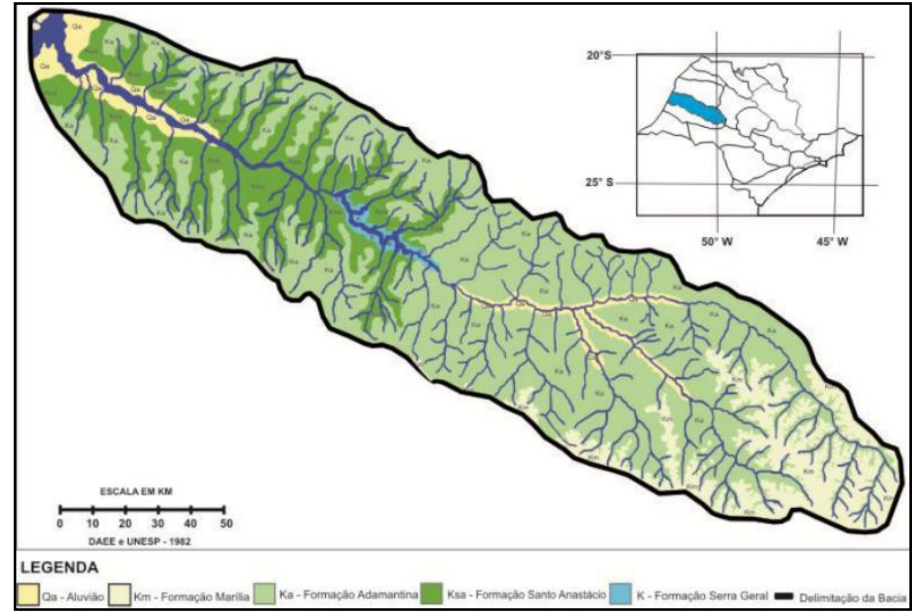

Fonte: Porto et al. (2013).

O relevo da área onde está localizado o Sítio Arqueológico Aldeia I, configura-se predominantemente, por colinas amplas, caracterizadas por topos extensos e aplainados, vertentes com perfis retilíneos e convexos ( $\mathrm{CBH}$ AP, 1997).

O Sítio Arqueológico Aldeia I encontra-se em área de baixa vertente, posição que, em relação ao relevo, é uma das características dos assentamentos Guarani, destacados por Faccio
(1992, 1998 e 2011), bem como por Morais (1999/2000).

A Figura 7 apresenta a localização do sítio arqueológico em relação ao curso d'água mais próximo e o perfil topográfico do sítio. Podemos perceber, na Figura 7, que o entorno é marcado pelo plantio de cana-de-açúcar, são poucas as espécies arbóreas e, por meio do perfil topográfico, observamos que a vertente onde está localizado configura-se como retilínea.

Figura 7. Localização e perfil topográfico do Sítio Arqueológico Aldeia, Junqueirópolis, SP
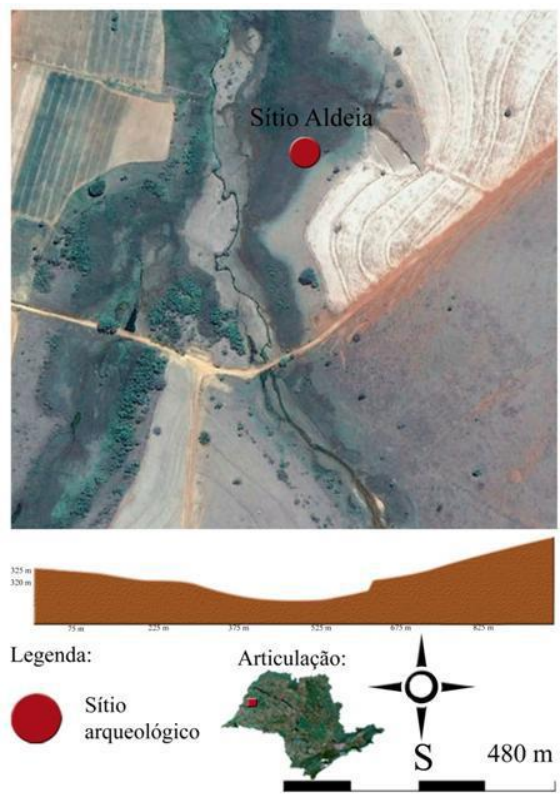

Fonte: Faccio et al. (2013) 
O Sítio Aldeia I dista 50 quilômetros do Rio Paraná e 12,5 quilômetros do Rio Aguapeí, aproximando-se do Ribeirão Taquaruçu, em torno de 200 m. O Ribeirão Taquaraçu, curso d'água mais próximo da área, é um curso d'água assoreado, devido às práticas agrícolas e de pastoreio, ocorridas ao longo de décadas no seu entorno. Além dessas práticas, verifica-se ausência da mata de galeria, o que agrava a conservação do Ribeirão Taquaruçu (Foto 1).

Podemos observar que a vegetação predominante no entorno do Ribeirão Taquaruçu são as heliófilas (pioneiras), vegetação que ocupa áreas degradadas e aceita radiação solar direta. A espécie mais visível nas fotos apresentadas são as gramíneas. Como relatado por Faccio et al. (2013), o sítio encontra-se em avançado grau de degradação o que reflete os impactos causados pelo cultivo da cana-de-açúcar.

Faccio et al. (2013), relatam o predomínio dos Argissolos Vermelho-Amarelos (PVA) e Latossolos Vermelhos (LVA).

Foto 1. Ribeirão Taquaruçu na área do Sítio Arqueológico Aldeia I, Município de Junqueirópolis, SP

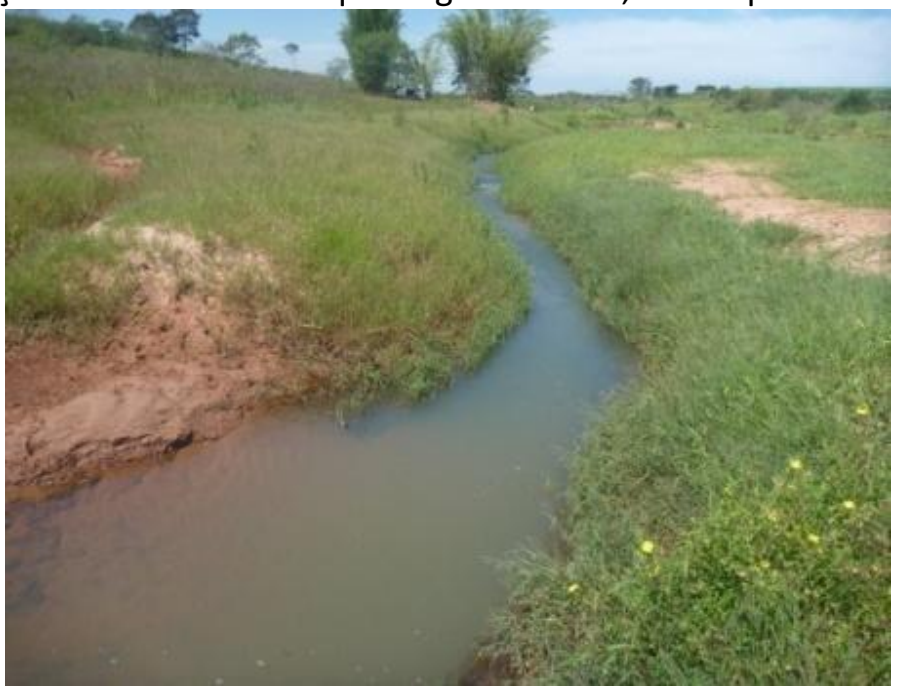

Fonte: Faccio et al. (2013).

O sítio arqueológico apresenta extensão de $150 \times 100 \mathrm{~m}\left(15.000 \mathrm{~m}^{2}\right)$ e baixa densidade de artefatos. Os vestígios foram encontrados na área de plantio de cana-de-açúcar, sendo que 31 peças estavam em superfície. Junto das cerâmicas, encontrou-se apenas um artefato lítico como podemos observar na Figura 8.

Foram encontrados 31 fragmentos de cerâmica em superfície e 24 em profundidade, sendo que seis fragmentos foram encontrados no nível de 0 a 10 centímetros, quatro fragmentos no nível de 10 a 20 centímetros, seis de 20 a 30, cinco fragmentos no nível de 30 a 40 , dois fragmentos de 40 a 50 e um fragmento no nível de 50 a 60, fato que nos permite classificar o sítio arqueológico analisado como sítio de superfície, quanto ao contexto deposicional dos materiais arqueológicos, e a céu aberto devido ao contexto de exposição desses materiais.

Todos os fragmentos encontram-se fragmentados, fato esse relacionado à movimentação tanto vertical quanto horizontal das cerâmicas, pelo uso do subsolador para movimentação do solo, que atinge até sete centímetros de profundidade, característica que é a realidade da maioria dos sítios arqueológicos evidenciados com a prática da arqueologia preventiva.

Para as análises dos materiais arqueológicos cerâmicos do Sítio Arqueológico Aldeia I, foram utilizados 38 fragmentos, uma vez que os demais são fragmentos muito pequenos, provenientes da quebra das cerâmicas, ao longo do tempo. 
Figura 8. Sítio Arqueológico Aldeia, Município de Junqueirópolis, SP

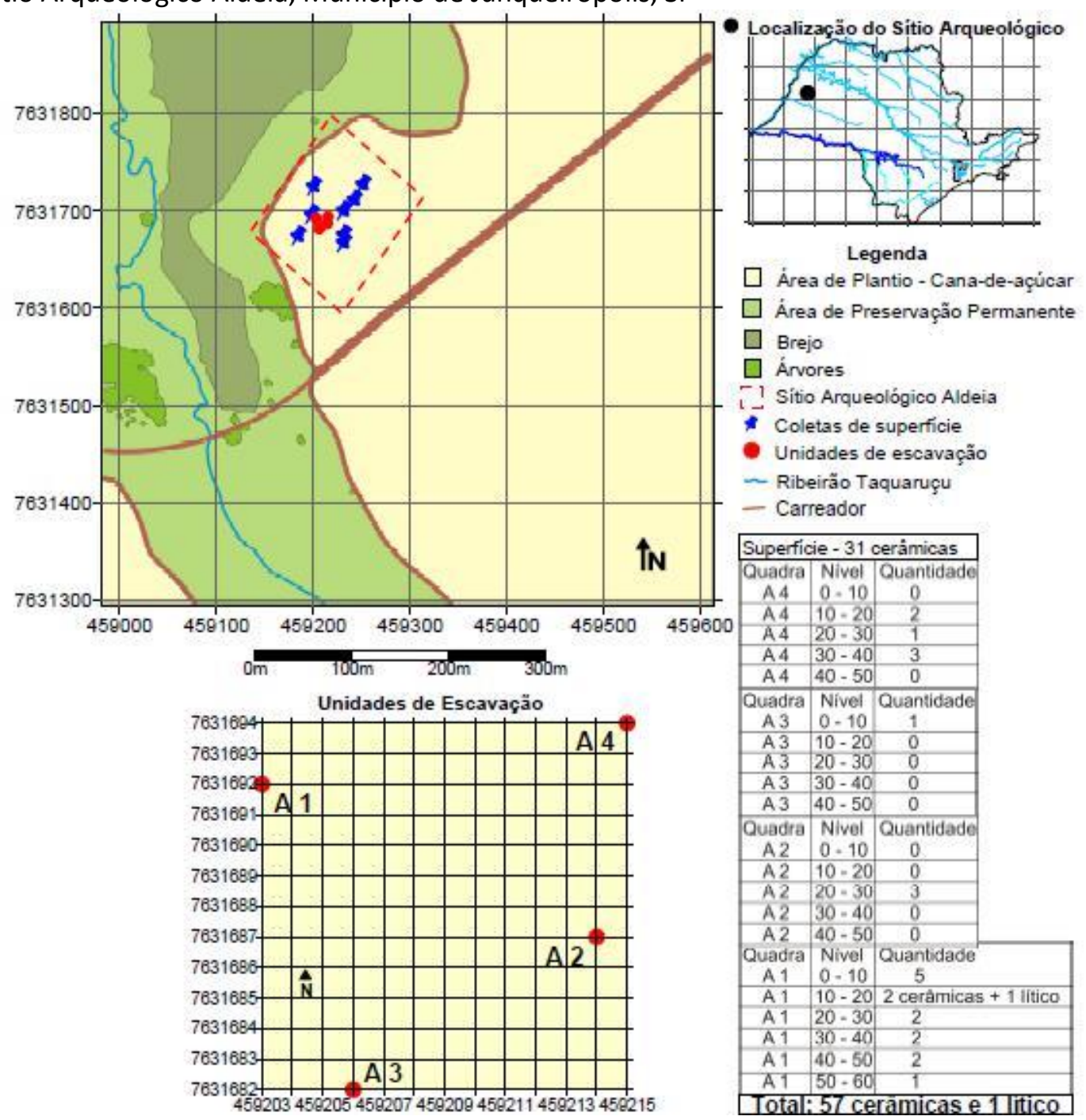

Fonte: Faccio et al (2013).

Analisamos o processo produtivo dos artefatos do Sítio Aldeia I em duas partes: uma primeira que corresponde aos elementos referentes à pasta (antiplástico, classificação da pasta, e espessura) e uma segunda que se dirige aos elementos do acabamento superficial (tratamento de superfície e decoração). A queima e a classe do fragmento seguirão, no final, para uma análise integrada com a conclusão das interpretações obtidas.

Para isso, analisamos 38 fragmentos cerâmicos, como foi dito, pois os demais constituíam fragmentos muito pequenos, provenientes da quebra das cerâmicas, ao longo do tempo.

Como exposto, o antiplástico é o elemento que interfere na plasticidade da pasta; em maior quantidade diminui sua plasticidade. Faccio (1998) explica,

neutralizar a
plasticidade da
argila, dar
condições para
boa secagem e
queima, aumentar
ou diminuir a
resistência do
choque térmico
ou mecânico,
diminuir ou
aumentar a
porosidade e
permeabilidade.
(FACCIO, 1998, p.
134)

Notamos na cerâmica do Sítio Aldeia I, que a presença de mineral junto com o caco moído foi encontrado em $53 \%$ dos fragmentos, já o mineral foi encontrado em $47 \%$ das peças (Tabela 6), fato que indica preferência por potes 
mais consistentes, já que o antiplástico caco moído diminui a plasticidade da argila, possibilitando a confecção de vasilhas maiores, com maior resistência para o cozimento de grãos.

Tabela 6. Tipo de antiplástico dos fragmentos cerâmicos do Sítio Arqueológico Aldeia.

\begin{tabular}{lll}
\hline Tipo Antiplástico & Quantidade & Frequência \\
\hline Mineral & 18 & $47 \%$ \\
\hline Mineral e Caco Moído & 20 & $53 \%$ \\
\hline Total & 38 & $100 \%$ \\
\hline
\end{tabular}

Fonte: A autora.

A classificação da pasta toma por base a delimitação sugerida por Brochado e La Salvia (1989), que apresentam, em sua estrutura, cinco tipos de pasta: dura (com presença mínima de argila e muito antiplástico), seca (predomínio de antiplástico, mas com representatividade de argila), mediamente plástica (representatividade igual entre os dois elementos), plástica (apresenta um aumento de argila e uma diminuição do antiplástico) e, por fim, aquela muito plástica (não existe praticamente 0 antiplástico).
Na classificação dos fragmentos do Sítio Aldeia I, dimensionamos três categorias de pasta: a dura, a intermediária e a plástica. Nota-se que $47 \%$ dos fragmentos apresentam-se com pasta plástica, 39\% intermediária e apenas 13\% dura (Tabela 7).

Nesta observação, destaca-se que os fragmentos que apresentaram como pasta dura são aqueles que têm uma alta quantidade de antiplástico, sendo quatro deles mineral associado ao caco moído e um apenas mineral.

Tabela 7. Classificação da pasta nos fragmentos cerâmicos do Sítio Arqueológico Aldeia

\begin{tabular}{lcl}
\hline Pasta & Quantidade & Frequência \\
\hline Dura & 5 & $13 \%$ \\
\hline Intermediária & 15 & $39 \%$ \\
\hline Plástica & 18 & $47 \%$ \\
\hline Total & 38 & $100 \%$ \\
\hline
\end{tabular}

Fonte: A autora.

Os fragmentos apresentaram, em $47 \%$ dos casos, espessura entre 1 e $2 \mathrm{~cm}$, seguidos por $39 \%$ que apresentaram espessura menor que 1 $\mathrm{cm}$ e $13 \%$ que apresentaram espessura maior que $2 \mathrm{~cm}$ (Tabela 8). Analisando essa categoria, observamos que os fragmentos mais espessos são os identificados com pasta dura. Aparentam ser de vasilhas de porte grande e quatro deles possuem como antiplástico o mineral associado ao caco moído, o que diminui a plasticidade e garante mais consistência.

Tabela 8. Variação da espessura dos fragmentos cerâmicos do Sítio Arqueológico Aldeia I

\begin{tabular}{llll}
\hline \multicolumn{1}{c}{ Espessura } & & Quantidade & Frequência \\
\hline Menor que $1 \mathrm{~cm}$ & 15 & $39 \%$ \\
\hline Entre 1 e $2 \mathrm{~cm}$ & 18 & $47 \%$ \\
\hline Maior que $2 \mathrm{~cm}$ & 5 & $13 \%$ \\
\hline Total & 38 & $100 \%$ \\
\hline
\end{tabular}

Fonte: A autora. 
Para avaliar o acabamento superficial, verificamos na análise o tratamento de superfície e a decoração tanto externa quanto interna do artefato.

Como La Salvia e Brochado (1989) afirmam, o acabamento tanto pode ser de intenção utilitária quanto para simples acabamento. Foram identificados em $84 \%$ dos fragmentos o alisamento na face interna e na face externa, seguido por $11 \%$ de alisamento de superfície da face interna sem alisamento externo, 3\% apresentam alisamento de superfície na face externa sem alisamento interno e em 3\% dos casos não foi possível identificar o tratamento de superfície (Tabela 9).

Tabela 9. Tipos de tratamento de superfície identificado nos fragmentos de cerâmica do Sítio Arqueológico Aldeia I

\begin{tabular}{lll}
\hline Tratamento de Superfície & Quantidade & Frequência \\
\hline Alisamento Externo s/ Alisamento Interno & 1 & $3 \%$ \\
\hline Alisamento Interno e Externo & 32 & $84 \%$ \\
\hline Alisamento Interno e s/ alisamento Externo & 4 & $11 \%$ \\
\hline Não Identificado & 1 & $3 \%$ \\
\hline Total & 38 & $100 \%$ \\
\hline
\end{tabular}

Fonte: A autora.

Os tipos de cerâmicas presentes no sítio em tela corresponderam, em $89 \%$ dos casos, ao liso na face interna e liso na externa. Apenas $5 \%$ dos fragmentos apresentaram pintura na face externa. No restante dos casos, não foi possível identificar a decoração da face interna, sendo a externa lisa (Tabela 10).

Para a avaliação da queima nos fragmentos, recorremos aos seis tipos de queima propostos por Faccio (1992): queima 1, com cor, apresenta-se uniforme variando do laranja--tijolo ao amarelo; queima 2, de cor uniforme variando do cinza-claro ao pardo; queima 3 , com núcleo central escuro com uma camada interna e uma externa clara; queima 4, de cor uniforme variando do cinza escuro ao preto; queima $5 \mathrm{com}$ camada clara na parte externa e uma camada escura na interna e, por fim, queima 6 que apresenta camada clara na parte interna e uma camada escura na externa.

Tabela 10. Tipos de decoração identificada nos fragmentos de cerâmica do Sítio Arqueológico Aldeia I

\begin{tabular}{lll}
\hline Tipo de decoração & Quantidade & Frequência \\
\hline Liso na face interna e externa & 34 & $89 \%$ \\
\hline $\begin{array}{l}\text { Liso na face interna e pintado } \\
\text { na face externa }\end{array}$ & 2 & $5 \%$ \\
\hline $\begin{array}{l}\text { Não identificado na face } \\
\text { interna e liso na face externa }\end{array}$ & 2 & $5 \%$ \\
\hline Total & 38 & $100 \%$ \\
\hline
\end{tabular}

Fonte: A autora.

Faccio (1998) explica que,

$$
\begin{aligned}
& \text { [...] a cor é } \\
& \text { elemento que } \\
& \text { permite definir o } \\
& \text { tipo de queima. } \\
& \text { As diferenças na } \\
& \text { cor indicam } \\
& \text { diferentes }
\end{aligned}
$$

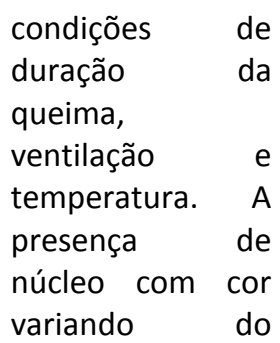




laranja ao
amarelo indicam
boa queima, com
ventilação
suficiente para
ocasionar
oxidação a
argila. A presença
de tons que
variam do cinza
ao preto indicam
uma queima
incompleta em
baixa
temperatura
tempo
insuficiente para
expelir toda a
matéria

carbonária da argila. (FACCIO, 1998, p. 135)

Foram identificados nos vestígios analisados os cinco primeiros tipos de queima, sendo que nenhum fragmento apresentou a queima 6. Observa-se maior ocorrência da queima 4, com 79\%, seguida da queima 1 e 2, com $8 \%$ cada e queima 3 e 5 com 3\% cada. Dentre os fragmentos de queima 4, 50\% foram classificados com pasta plástica, 33\% intermediária e $17 \%$ dura.

As frequências de ocorrência da queima nos vestígios analisados seguem registrados na Tabela 11.

Tabela 11. Variação da queima nos fragmentos cerâmicos do Sítio Arqueológico Aldeia I

\begin{tabular}{lll}
\hline Queima & Quantidade & Frequência \\
\hline Cor uniforme variando do laranja-tijolo ao amarelo & 3 & $8 \%$ \\
\hline Cor uniforme variando do cinza-claro ao pardo & 3 & $8 \%$ \\
\hline $\begin{array}{l}\text { Núcleo central escuro com uma camada interna e uma externa } \\
\text { clara }\end{array}$ & $3 \%$ \\
\hline Cor uniforme variando do cinza escuro ao preto & 30 & $\mathbf{7 9 \%}$ \\
\hline Camada clara na parte externa e uma camada escura na interna 1 & $3 \%$ \\
\hline Camada clara na parte interna e uma camada escura na externa- & - \\
\hline Total & $\mathbf{3 8}$ & $\mathbf{1 0 0 \%}$ \\
\hline
\end{tabular}

Fonte: A autora.

No sítio em tela, os fragmentos representaram a configuração quatro tipo de classes, conforme mostra a Tabela 12.

Tabela 12. Classe dos fragmentos cerâmicos do Sítio Arqueológico Aldeia I.

\begin{tabular}{|c|c|c|}
\hline Classe & & Frequência \\
\hline Base & 4 & $11 \%$ \\
\hline Borda & 4 & $11 \%$ \\
\hline Borda com suporte para tampa & 1 & $3 \%$ \\
\hline Parede & 29 & $76 \%$ \\
\hline Total & 38 & $100 \%$ \\
\hline
\end{tabular}

Fonte: A autora.

Observa-se o predomínio de fragmentos de parede, representando $76 \%$ da coleção, seguido por $11 \%$ de base, $11 \%$ de borda e $3 \%$ borda com suporte para tampa.

A análise possibilitou conhecer a cerâmica nos seus aspectos tecnotipológicos, as associando-as às cerâmicas da Tradição Arqueológica Tupiguarani (Atributo tradição exigido pela classificação no registro do cadastro nacional do IPHAN).

\section{CONCLUSÕES}

Ressaltamos que sítios arqueológicos como o Sítio Aldeia I, constituem--se de alto valor e relevância, e precisam ser objeto de pesquisas para que compreendamos a complexidade dos 
assentamentos humanos pretéritos e a interrelação entre eles.

Os sítios de pequeno porte apresentam valor para a compreensão das populações ameríndias, principalmente quando debatemos seus elementos em escala regional, tendo em vista que os colocamos em evidência, mesmo com as inúmeras limitações, discussões acerca da dispersão, movimentação e mobilidade dessas populações pelo território.

Assim, este estudo apresenta informações para o acúmulo de conhecimento a respeito da dispersão desses sítios pelo território, para que possamos entender, quando analisados em escala regional, a distribuição dessas populações pelo território brasileiro, rotas de migração e fronteiras culturais.

É efetiva a complexidade para o entendimento das diferentes relações desses povos entre si, bem como suas relações com o meio, ou seja, com suas práticas e organizações culturais, econômicas e políticas.

Nesse sentido, um sítio arqueológico de pequeno ou de grande porte, traz em si uma gama de variáveis capazes de compor uma narrativa coerente dos fatos passados e presentes em sua inter-relação contínua e dialética, pois, mesmo sobre forte impacto do agronegócio, do arado e do subsolador, artefatos resistem, deixam-se ficar na paisagem como herança.

Analisando os sítios arqueológicos pelo viés da paisagem, podemos compreender a geograficidade remanescente nesses vestígios, o modo de vida daquele povo. O valor simbólico desses solos ou os geoindicadores (com as melhores fontes de matéria-prima, como solo argiloso para o trabalho em barro), os rios para a pesca e as matas para caça. No caso dos sítios de pequeno porte, podemos analisar a distância de cursos d'água, a disponibilidade de matériaprima, a variabilidade e quantidade das peças, fatores que influenciam na interpretação da funcionalidade desses sítios para as populações pretéritas, bem como para compreender o Sistema Regional de Ocupação Indígena dessa região.

Assim, acreditamos colaborar, com o registro desses bens. E, por essa razão, defendemos que o papel dos pesquisadores inclinados à temática do patrimônio deve ser o de defender os remanescentes das ocupações humanas pretéritas em quaisquer condições, independentemente da noção de integridade e ou relevância imposta.

\section{REFERÊNCIAS}

BROCHADO, J. A Expansão dos Tupi e da Cerâmica da Tradição Policrômica Amazônica. São Paulo: Dédalo 1989. p. 65-82.

FACCIO, N. B. Estudo do Sítio Arqueológico Alvim no Contexto do Projeto Paranapanema. 1992. 154 f. Dissertação de Mestrado (Mestrado em Ciências) - Faculdade de Filosofia, Letras e Ciências Humanas, Universidade de São Paulo, São Paulo, 1992.

FACCIO, N. B. Arqueologia do cenário das ocupações horticultoras da Capivara, Baixo Paranapanema - SP. 1998. Tese (Doutorado em Arqueologia) - Faculdade de Filosofia, Letras e Ciências Humanas da Universidade de São Paulo. São Paulo, 1998.

FACCIO, N. B. Arqueologia Guarani na Área do Projeto Paranapanema: estudo dos sítios de lepê, SP. V. I. 2011. Tese (Livre Docência em Arqueologia e Etnografia) - Museu de Arqueologia e Etnografia, Programa de PósGraduação em Arqueologia - Universidade de São Paulo, São Paulo, 2011.

FACCIO, N. B. et al. Rio Vermelho Açúcar e Álcool s/a, Junqueirópolis/SP. Relatório de Prospecção Arqueológica e Programa de Educação Patrimonial. IPHAN, SP, 2013.

LA SALVIA, F. E BROCHADO, J. P. Cerâmica guarani. Porto Alegre: Posenato Arte e Cultura, 1989.

LATHRAP, D. O Alto Amazonas. Lisboa: Verbo, 1975.

MORAIS, J. L. A Propósito da Interdisciplinaridade em Arqueologia. Revista do Museu Paulista, V.3. P. 56-57, 1986.

MORAIS, J. L. A Ocupação do Espaço em Função do Relevo e o Aproveitamento das Reservas Petrográficas por Populações Pré-Históricas do Paranapanema, SP. São Paulo: Editora do Fundo de Pesquisas do Museu Paulista da USP, 1979. p. v. 6. 
MORAIS, J. L. Arqueologia da região Sudeste. Revista USP, São Paulo, n.44, p. 194-217, dez/fev. 1999/2000.

DOI:

https://doi.org/10.11606/issn.2316-

9036.v0i44p194-217.

NOELLI, F. S. Sem tekoá não há teko (Em busca de um modelo etnoarqueológico da aldeia e da subsistência guarani e sua aplicação a uma área de domínio no Delta Jacuí - RS). Dissertação (Mestrado em Arqueologia. Porto Alegre, PUCRS, 1993. $728 f$.

NOELLI, F. A Ocupação Humana na Região Sul do Brasil: arqueologia, debates e perspectivas18722000. Revista USP, São Paulo, 1999-2000, 44:218269.

PEREIRA, D. L. T. Arqueologia Guarani na bacia do Rio Santo Anastácio - SP: estudo do Sítio Célia Maria. 2011. 168 f. Dissertação (Mestrado em Arqueologia) - Universidade de São Paulo. USP, São Paulo, 2011.

PALLESTRINI, L. O sítio arqueológico Jango Luís. Revista do Museu Paulista, São Paulo, v. 18: 2656, 1968-1969.
PALLESTRINI, L.; MORAIS, J. L. Prassévichus, Aldeia Pré-Histórica no Município de Itaberá, SP. Revista do Museu Paulista, Nova Série-Volume XXIX: 151-161, 1983-1984.

PORTO, D. R. et al. Análise Morfotectônica da Bacia Hidrográfica do Rio Aguapeí, Planalto Ocidental Paulista, mediante Fluviomorfometria e Fotointerpretação. São Paulo, UNESP, Geociências, v. 32, n.2, p. 227-246, 2013.

SOARES, A. L. Guarani: organização social e Arqueologia. Porto Alegre: EDIPUCRS, 1997.

TOSO, D. M. S. Estudo de sítios arqueológicos do Baixo Rio Aguapeí. 2018. Trabalho de Graduação de Curso (Curso de Geografia) - Universidade Estadual Paulista, Presidente Prudente, 2018.

CBH-AP. Comitê das Bacias Hidrográficas dos Rios Aguapeí e Peixe. Relatório Zero. 1997. Disponível em: http://cbhap.org/publicacoes/relatorioz/. Acesso em: 20 out. 2018. 